\title{
THE "MIND-MAP" TECHNIQUE AS ONE OF THE INNOVATIVE METHODS OF VISUAL TEACHING METHOD
}

\author{
Jamilya Kenzhebaeva ${ }^{1}$, Tatyana Kokhanover ${ }^{2}$ \\ ${ }^{1}$ E.A Buketov Karaganda University, Kazakhstan \\ ${ }^{2}$ E.A Buketov Karaganda University, Kazakhstan
}

ORCID iD: 0000-0002-3353-8742

\begin{abstract}
The article is devoted to the training of the Mind-map technique and its implementation in the educational process. Personality begins to form from early childhood. The education system, like all other institutions of society, strives to fully meet the new demands of this society. The child should be able to work freely with information. Be able to receive, process and use it in the context he needs. With the help of pictures, diagrams, intelligence maps, it is easier to pose a problem and build a strategy for solving it. Therefore, in order to improve the effectiveness of teaching, we need to introduce and develop similar technologies for working with students.
\end{abstract}

\section{INTRODUCTION}

Modern life, information society are in endless dynamics, constant development. And humanity, as a whole, is undoubtedly progressing day by day. Nowadays, a person must fully meet all the requirements and criteria that society puts forward for him. Possess the necessary set of qualities, skills, knowledge, competencies. Personality begins to form from early childhood. The foundations of modern society and the laws of its development are laid for the child. Since early childhood, the child is being prepared for the future, adult life. Naturally, the most important factor in this process is the family, but do not underestimate the role of the education system. The education system, like all other institutions of society, strives to fully meet the new demands of this society [Arsova, 2021; Arsova, 2020; Petrova, Popova \& Dejniak, 2020; Valdmane et al, 2020]. The school itself has a great influence on the formation of the future personality.

Schoolchildren feel great emotional satisfaction from research activities. They like to think, to make independent discoveries. Therefore, it is necessary to make changes to the established forms of submission of the material. To date, charted understanding and visualization is a necessary part of thinking. Visual understanding is an intellectual activity based on the operation of visual spatially structured schemes.

The basis of visual thinking is visual - imaginative thinking, where when a word is mentioned, an image first of all pops up, and not a concept that reveals the meaning of this term. An important advantage of visual thinking is the ability to see all the material at once. When you organize all the information on one plane - a board or a sheet, you get the opportunity to see the whole picture of the project. There are wonderful tools for this - mental maps (mind-maps). With the help of pictures, diagrams, intelligence maps, it is easier to pose a problem and build a strategy for solving it. Therefore, in order to improve the effectiveness of teaching, we need to introduce and develop similar technologies for working with students. Mental maps (intelligence maps) are a tool that allows you to: effectively structure and process information, as well as think using all your creative and intellectual potential.

Of course, any teacher in his pedagogical work has met with the problem of building an exciting and at the same time effective lesson. Any teacher wants to organize an atmosphere of creativity in the classroom, students' interest, their complete emancipation in the pedagogical process. Everyone knows that the activities of a child in the classroom, his ability to show his abilities, build and state personal conclusions contribute to the perception of the material much more than ordinary activities. Consequently, in recent years, technologies that develop thinking and activate its activity have become famous in the system of domestic education. One of these technologies is the mind-map 
method. Despite the fact that it undoubtedly responds to all the current requirements of the education system, it provides the teacher with a huge stock of unique ways and thinking methods that absolutely contribute to the creation of a creative and productive lesson. Mind-map, also known as a mental map or association map, is a means of creating joint system thinking using schemas. And it can also be presented as a comfortable alternative recording method. The method of using the associative map was designed by psychologist Tony Buzen, who at the time of his training was in search of a method of effective memorization and systematization of information [Buzen, 2018].

"Mind mapping" appeared at the end of the twentieth century, and was invented by a British psychologist working on the development of methods for organizing thinking, memorizing and developing creativity Tony Buzan [Buzen, 2018]. He is an expert in the field of self-development, memory formation and thinking. This technique of working with information in different varieties, or under other names, was even before Tony Buzen. But, besides, only he became the distributor of the idea of "mental maps" as an effective method of working with the material. The associative map is carried out in a variant of a linear scheme, which depicts words, thoughts, puzzles or some concepts united by branches going through a key concept or ideas.

And in order for both hemispheres to be involved, when creating "mind maps", Buzen suggests depicting not only the shape of radial rays, like neurons, but also coloring branches diverging from the main theme in different colors [Buzen, 2018]. Then the brain perceives, understands and remembers information better. With this approach, a person activates the so-called radiant thinking, when thoughts, like branches on a tree, diverge from their core - from the center to the periphery, from the central (main) idea (theme) - to associative ideas (subtopics) and further - to smaller associations (details).

This method is based on the principle of "radiant thinking", which belongs to associative thought processes, the starting point of which is the key object. While "radial thinking" is mental thinking, the starting point of which is the main image. Rays radiate from the central image in different order all over the sheet. Above them, the main words are described or images are drawn that unite with branching lines. A similar mark allows the intelligence map to expand immeasurably and be constantly supplemented. This demonstrates an infinite number of possible associations and, consequently, the unlimited possibilities of the brain. Mind-map can be used for the foundation, visualization, structuring and systematization of thoughts, as well as as a means for education, organization, problem solving, decision-making, when writing articles. Mind-map is also a favorable and effective technique for visualizing thinking and other writing. It is allowed to use it in order to form fresh thoughts, fix ideas, review and organize data, and make decisions. This is by no means a generally accepted, but a very natural way of organizing thinking, including a number of undeniable advantages over conventional recording methods.

If we talk about the application of the method in the educational concept, then we will have a chance to use the technology in order to resolve subsequent issues:

1) taking notes of books;

2) organization of the material according to the selected topic;

3) solving creative tasks;

4) mental assault;

5) presentations;

6) drawing up a plan and organizing projects of varying complexity;

7) formation of case sheets;

8) formation of intellectual capabilities.

Mind-map has a list of differences from the traditional form of the concept of information:

1) it is not difficult to identify the main idea when it is located in the center of the sheet in the form of a catchy graphic sample;

2) interest is concentrated not on random information, but on significant issues;

3 ) the relative importance of each thought is clearly visible. The most significant ideas are focused closer to the center, and to lesser extent significant ones are focused in the periphery; 
4) the used material is quickly and successfully remembered and reflected with the help of its multi-color and multidimensional representation;

5) the highly structured view of the map makes it possible to add new information to the map without special efforts;

6) by making a mind-map, or drawing ideas in another way, students demonstrate an individual method of perception, processing and concept of information.

The work becomes observable, moreover, the skills formed by the students during the work also become observable. The method of intelligence maps makes it possible to: create communicative competence in the course of group work, create skills associated with perception, processing and data exchange (taking notes, annotating, involvement in analytical reviews), improve all types of memory (short-term, long-term, semantic, figurative) of students, modernize the teaching process. The following advantages of mind-map technology differ.

1) Data is easier to capture, faster and to a lesser extent in volume.

2) When reading the map, there is a connection in the informative block, structure and logic.

3) When using mental maps, thinking (creative and logical), memory and fantasy are formed.

4) When using mental maps, creative processes are involved and the full potential is used, since we use two hemispheres of the brain.

5) Information is remembered instantly, in the highest quality and in substantial volumes.

6) The method of mental maps is easy to learn. The method of mental maps corresponds to the real needs of students and is suitable for the age level of their formation. It makes it possible to work interactively according to exam preparation in the system, using a large-block method of consolidating knowledge and saving time. The acquired knowledge of students is stored in memory for a much longer time, and part of the mastered material is significantly higher.

In addition, the process of building a mind-map makes learning creative and exciting. Drawing up their own intelligence maps gives students the opportunity to identify weaknesses in the knowledge of the subject, helps to learn how to work independently with educational and reference materials, develops personal qualities, intelligence, spatial thinking. Depending on the scope of its application, the following types of intelligence cards are distinguished:

1. Standard maps.

This is a set of classic intelligence cards that serve to assimilate knowledge, record ideas and reveal one's own individuality.

2. Speed maps or lightning maps.

These are intelligence cards that stimulate mental processes. A map can be a short one-color synopsis made before a speech or report.

3. Master maps.

These are very voluminous maps for an entire field of knowledge, for example, based on the results of a quarter or half a year at school. They are often compiled continuously and serve as a general overview of the topic.

4. Mega-maps.

The cards connected to each other are called mega-cards. A central map with a relatively small number of levels is linked to subsequent maps that present details or additional aspects.

Mind-map technology can be used in different lessons, in different classes, that is, we can say that it is perceived by children of any age. Therefore, it is worth highlighting that in the current concept of education, the teacher is not considered the basis of knowledge in any way, he is only an intermediary between the child and the baggage of knowledge that he acquires. Clearly, the main task of a teacher is the ability to interest teenagers in learning activities.

Create all possible conditions for comfortable, and, nevertheless, effective work in the classroom. The manner of presentation of the material is important, the use of various methods, pedagogical techniques, the ability of the teacher to explain the material intelligibly, but at the same time fascinatingly. Pedagogical activity should it should be aimed at the formation of children's interest and curiosity. The whole educational process should meet all the cognitive needs of 
students. The child will be interested in such activities, where he himself will be able to present the material, be a participant in scientific work, research.

\section{CONCLUSION}

The practical significance of educational activity is important to a teenager, it is important for him to be a discoverer of any phenomena. Mind-map technology is very versatile. It can be used as a lesson element, and you can also build a whole lesson with the construction of mental maps. As an element of the lesson, the technology can be used at any stage of the lesson updating knowledge, repetition, primary and consolidation. Intelligence cards can be individual, and they can also be made up of a group of students. It can be used as a homework assignment. It all depends on the creative potential and creativity of the teacher.

"Time is the greatest of innovators," said English the philosopher Francis Bacon. Time affects all spheres of human life, including education, periodically requiring its renewal. Today it becomes clear: it is impossible to "enter" the "new" time with the old standards. As mass practice has shown, the main task of the Russian educational policy is to ensure the modern quality of education.

Thus, we can say that "mind mapping" is an innovative, creative, simple, accessible, interesting and useful tool in life, work, training for the organization and visual expression of our thoughts, for the development of thinking and creativity. It also helps to better assimilate and remember information.

\section{REFERENCES:}

Abramova G.S.(2009) Age psychology: A textbook for university students. - M.: Academy

Akimenko V.M.(2012) The use of Intellectual maps in the learning process [Text]/ V.M. Akimenko// Elementary school plus before and after.-.-No.7.-pp.344-37.

Arsova, D. (2021). The role of e-books in the digitalisation process in primary school. "Innovations in technology and education": proceedings of XIV International scientific conference "Innovations in technology and education", 26 march 2021 г.: Kuzbass State Technical University, Belovo, Russia; 2021. - vol. 3., pp. 53-58 (in BG)

Arsova, D. (2020). Developing of the elementary school students skills in a digital world // "Innovations in technology and education": proceedings of XIII International scientific conference "Innovations in technology and education", 26 march 2020 г.: Kuzbass State Technical University, Belovo, Russia; 2020. - vol. 4., pp. 55-60. ISBN 978-5-00137-065-9

Buzen, T. (1991) Use both sides of Your Brain, The Plume Penguin Group, January

Buzen, T. (1993). The book "Mind Map", September 6, 1993, ISBN 0-563-36373-8

Petrova, M.; Popova, L.; Dejniak, D. (2020). Children's University activities as implementation of the third mission of higher education institution. Strategies for Policy in Science and Education, Volume: 28, Issue: 2, Pages 161-171

Vadim Berlin, http://free-psycho.ru/chto-takoe-majndme-pping-i-karty-myslej/

Valdmane, L., Zarina, S., Iliško, D., Badjanova, J., Petrova, M. (2020). Empowering of digital and media literacy of primary school teachers in Latvia. EDULEARN20, 12th annual International Conference on Education and New Learning Technologies, 6th - 7th of July, 2020, Proceedings of EDULEARN20 Conference 6th-7th July 2020, ISBN: 978-84-09-17979-4, ISSN: 2340-1117, pp.4022-4029, DOI:10.21125/edulearn.2020, Publisher: IATED; 10.21125/edulearn.2020.1087

Willis, Cl.(2006) "Mind Maps as active learning tools", Journal of Computer Science in Colleges.

http://megapoisk.com/majndmepping-tvorcheskij-podhod-k-reshenijuzadach\#v-chem

http://www.mindmap.ru/intellekt-karty/application/planning/time planning/ 